\title{
Kebutuhan Kompetensi Dakwah Healing Dan Konseling di Dunia Kerja
}

\author{
Radhiya Bustan $^{1 *}$, Masni Erika Firmiana ${ }^{2}$ \\ ${ }^{1,2)}$ Fakultas Psikologi dan Pendidikan, Universitas Al Azhar Indonesia, Jl.Sisingamangaraja, Jakarta 12110 \\ Tel. (021) 7244456, fax. (021) 7244767, "email: radhiya bustan@uai.ac.id
}

\begin{abstract}
There is a gap between the outcomes of higher education and the demands of competence in the workplace (Observation Teichler, 1997, 1999; Yorke and Knight, 2006). It is necessary to anticipate and evaluation conducted by the universities to the needs of the working world of the competence of its graduates. For this reason, preaches study program of Healing and Counseling at University of Al Azhar Indonesia needs to put through research, whether Healing and Counseling Program will be able to achieve the vision of its mission into educational institutions that can print a preacher who can do the required counseling Islam in society and the world of work today. This study aims for Healing and Counseling Studies Program to conduct an evaluation of the competencies needed by the real world of work in society and to adapt appropriate teaching curriculum. The results showed that the competence of graduates of Healing and Counseling Program UAI was needed in the world of work and competence in the appropriate field for Healing and Counseling is generally associated with human resources (HR) or Human Resources Department, namely as a counselor, therapist, spiritual counselor / preachers, volunteers for various family problems, physical, educational, religious, Islamic law, and violence.
\end{abstract}

Keywords - Competency, preaches, Healing and Counseling

\section{PENDAHULUAN}

$\mathrm{P}$ erubahan yang cepat di dunia kerja sebagai akibat dari globalisasi dunia kerja dan revolusi di bidang teknologi serta berbagai disiplin science lainnya menuntut adanya antisipasi dan evaluasi yang dilakukan oleh perguruan tinggi terhadap kompetensi lulusan yang dibutuhkan di dunia kerja. Berdasarkan observasi Teichler (1997; 1999); Yorke dan Knight (2006) terdapat jurang antara outcome pendidikan tinggi dan tuntutan kompetensi di dunia kerja.

Di bidang dakwah, informasi mengenai kompetensi baik dari pihak lulusan maupun pengguna masih sangat kurang. Dakwah selama ini hanya dipersepsikan sebagai sebuah ceramah agama yang dilakukan di mimbar atau di forumforum agama, kurang melirik kepada kebutuhankebutuhan individu, sangat massal, satu arah, dan berbicara sangat normatif tanpa memperhatikan kondisi objektif dari individu bersangkutan (differences of individual). Padahal menurut ilmu psikologi, bertolak dari kondisi objektif sangatlah penting untuk memahami manusia.

Muncul banyak kritik terhadap dakwah yang membuat dakwah kurang diminati masyarakat dan dunia kerja. Sementara itu, kompleksitas kehidupan modern membutuhkan ditegakkannya agama dalam kehidupan masyarakat dan dunia kerja, untuk itu bidang dakwah perlu digarap dengan lebih baik (Izzuddin, 2006). Dakwah pada masa kini harus diefektifkan lagi dengan cara yang lebih dapat diterima masyarakat, dengan lebih memperhatikan apek-aspek psikologis. Healing dan konseling berdasarkan konsep-konsep Al-Qur'an dan Hadits adalah salah satu pendekatan dakwah yang dapat menjawab kebutuhan psikologis masyarakat saat ini. Hal ini berimplikasi pada besarnya tuntutan kebutuhan terhadap sarjana-sarjana muslim yang memiliki kemampuan dalam menangani masalahmasalah sosial, sejalan dengan semakin meningkatnya problematika sosial seperti kondisi alienasi, stres, dan depresi mental akibat penyakit atau tekanan di lingkungan tempat kerja, goncangan-goncangan dalam perkawinan dan keluarga, kemiskinan, kecanduan obat terlarang, kriminalitas, konflik etnik dan agama, bencana alam, dan lainnya. 
Universitas Al Azhar Indonesia (UAI) telah membuka Progam Studi Healing dan Konseling untuk melakukan dakwah kepada masyarakat dengan memperhatikan kondisi psikologis individu bersangkutan. Program Studi Healing dan Konseling UAI mencetak lulusan-lulusan yang mampu melakukan konseling Islam. Kurikulum dan Mata Kuliah Program Studi Healing dan Konseling merupakan kombinasi antara keislaman (fikih, tasawuf dan kalam) serta ilmu dakwah, konseling, psikologi, komunikasi dan pendidikan. Dengan kombinasi seperti itu, lulusannya diharapkan akan memiliki bekal untuk berperan sebagai praktisi dakwah Healing dan Konseling yang mampu membantu masyarakat dan individu dalam menghadapi tantangan dunia modern. Healing dan konseling dilakukan dengan konsep-konsep Islam yang tidak hanya spiritual, tetapi integrasi dari berbagai konsep pemikiran (tauhidi).

Berbagai lembaga yang melakukan program bantuan konseling seperti BP4 (Badan Penasehat dan Penyelesaian Perselisihan Perkawinan), RSKO (Rumah Sakit Ketergantungan Obat), Rumah Sakit Jiwa, Klinik Holistik, Lembaga Pemasyarakatan, Lembaga Swadaya Masyarakat (LSM) atau Clubclub kemanusiaan seyogyanya sangat membutuhkan sumber daya manusia lulusan Healing dan Konseling. Akan tetapi, program studi ini masih belum tersosialisasi di masyarakat dan dunia kerja. Untuk itu perlu dilalukan penelitian, apakah Program Studi Healing dan Konseling Universitas Al Azhar Indonesia akan dapat mencapai visi misinya menjadi lembaga pendidikan yang dapat mencetak da'i yang mampu melakukan konseling Islam yang dibutuhkan di masyarakat dan dunia kerja saat ini. Kompetensi seperti apakah yang dibutuhkan di dunia kerja saat ini? Apakah kompetensi lulusan Healing dan Konseling benarbenar dibutuhkan di dunia kerja? Dan bidang apa saja yang bisa ditempati oleh lulusan Healing dan Konseling dengan kompetensi yang dimilikinya?

Dengan hasil penelitian ini diharapkan Program Studi Healing dan Konseling dapat melakukan evaluasi terhadap kompetensi yang dibutuhkan oleh dunia kerja yang riil di masyarakat agar dapat menyesuaikan kurikulum pengajaran yang tepat sehingga mampu melahirkan lulusan yang kompetitif dan dibutuhkan di dunia kerja.

\section{Tujuan dan Manfaat Penelitian}

Penelitian ini bertujuan untuk mengetahui kebutuhan dunia kerja terhadap kompetensi lulusan Dakwah Healing dan Konseling.

\section{Manfaat penelitian :}

a. Secara praktis : dapat memberikan informasi yang dapat membantu pengambil kebijakan, terutama dalam bidang kurikulum Dakwah Healing dan Konseling untuk dapat melakukan evaluasi kebutuhan kompetensi di dunia kerja, serta dapat memberikan sumbangan informasi bagi dunia kerja dan lulusan Healing dan Konseling mengenai bidang yang sesuai bagi penempatan mereka di dunia kerja.

b. Secara teoritis : memberikan sumbangan pengetahuan tentang aplikasi teori-teori yang berkaitan dengan kompetensi Healing dan Konseling.

\section{Hasil yang Diharapkan}

Hasil penelitian ini diharapkan dapat membantu mengarahkan pihak Program Studi, Fakultas, serta Universitas dalam membuat dan menyusun kurikulum yang sesuai dengan kebutuhan dunia kerja. Dengan demikian, baik pihak Program Studi, Fakultas, maupun Universitas mampu melahirkan lulusan yang kompetitif dan dibutuhkan di dunia kerja. Hal ini akan dapat meningkatkan peringkat Program Studi, Fakultas, dan seterusnya Universitas. Lebih jauh, hal ini akan membuat Program Studi Healing dan Konseling maupun Fakultas Psikologi dan Pendidikan Universitas Al Azhar Indonesia sebagai salah satu pilihan utama bagi masyarakat dalam melanjutkan pendidikan tinggi.

\section{KAJIAN TEORI}

Kompetensi adalah seperangkat tindakan cerdas, penuh tanggungjawab yang dimiliki seseorang sebagai syarat untuk dianggap mampu oleh masyarakat dalam melaksanakan tugas-tugas di bidang pekerjaan tertentu (SK Mendiknas No. 045/U/2002, Ps. 21). Kompetensi berasal dari bahasa Inggris yang dikenal dengan istilah competency, competence, dan competent yang arti satu sama lainnya relatif sangat tipis. Competency merupakan kata benda dari competence yakni kecakapan. Competence selain berarti kecakapan dan kemampuan juga berarti wewenang. Juga dapat diartikan sebagai keadaan yang sesuai, memadai, atau cocok. Sedangkan competent sebagai kata sifat yang berarti cakap, mampu, dan tangkas. R. Palan dalam bukunya "Competency Management - A Practicioners's Guide”, terjemahan (2007) 
mengungkapkan competency (kompetensi) merupakan deskripsi mengenai perilaku, sementara competence (kecakapan) sebagai deskripsi tugas atau pekerjaan. Menurut Palan, kompetensi merujuk kepada karakteristik yang mendasari perilaku yang menggambarkan motif, karakteristik pribadi (ciri khas), konsep diri, nilai-nilai, pengetahuan atau keahlian yang dibawa seseorang yang berkinerja unggul.

Sejalan dengan kebijakan Direktoral Jenderal Pendidikan Tinggi Departemen Pendidikan Nasional (Diknas) dan Direktorat Jenderal Pendidikan Islam Departemen Agama (Depag), Program Studi Healing dan Konseling Universitas Al Azhar Indonesia juga menerapkan Kurikulum Berbasis Kompetensi (KBK). Kurikulum Berbasis Kompetensi merupakan jenis kurikulum yang menekankan sistem pembelajaran yang bervariasi antara pembelajaran di dalam kelas, praktikum, dan kegiatan lain di luar kelas yang menekankan kepada life skill. Ciri lain dari kurikulum berbasis kompetensi adalah penekanan kepada spesialisasi program studi masing-masing (Pedoman akademik FDK UIN Jakarta, 2006). Dengan demikian, pada program studi Healing dan Konseling beban mata kuliah program studinya mengambil porsi sekitar $65 \%$ dari keseluruhan mata kuliah yang wajib diambil mahasiswa.

Mengikut studi dari Fakultas Kesehatan Masyarakat Universitas Indonesia (FKMUI) yang berjudul "Kompetensi yang Dibutuhkan dalam Dunia Kerja" yang ditulis oleh Ahmad Syafiq dan Sandra Fikawati menjelaskan bahwa beberapa pergeseran dalam hal kompetensi dunia kerja yang terjadi dewasa ini meliputi dinamika hubungan antara pendidikan tinggi dan dunia kerja. Beberapa pergeseran penting yang terjadi meliputi peningkatan pengangguran terdidik, berubahnya struktur sosio-ekonomi dan politik global yang mempengaruhi pasar dunia kerja dan perkembangan ilmu pengetahuan dan teknologi yang pesat sehingga menyebabkan terjadinya berbagai perubahan mendasar dalam hal kualifikasi, kompetensi, dan persyaratan untuk memasuki dunia kerja.

Berdasarkan tulisan tersebut, Proram Studi Dakwah Healing dan Konseling Universitas Al Azhar Indonesia ingin melakukan survei terhadap kebutuhan dunia kerja saat ini terhadap kompetensi yang dimiliki oleh lulusan Healing dan Konseling yang dapat digunakan sebagai evaluasi kompetensi lulusan melalui kurikulum.

\section{HASIL PENELITIAN}

\section{Gambaran Umum Subjek Penelitian}

Subjek penelitian adalah 43 orang dari berbagai Perusahaan/Instansi pemerintah maupun swasta serta Lembaga-lembaga Swadaya Masyarakat.

\section{Hasil Utama Penelitian}

Pengolahan data dalam penelitian ini menggunakan jenis statistika deskriptif, yang merupakan metoda untuk memberikan gambaran menyeluruh tentang suatu atau beberapa kelompok dengan cara menyusun dan merangkum data kelompok/sampel.

Analisis data statistik dilakukan dengan distribusi frekuensi dengan ciri-ciri sebagai berikut:

a. Merupakan cara yang digunakan untuk mengorganisasi dan merangkum data agar lebih mudah dipahami

b. Menunjukkan seluruh skor yang ada dan frekuensi kemunculannya

c. Distribusi hasil pengukuran diletakkan dalam garis bilangan

d. Distribusi selalu berkaitan dengan frekuensi

Hasil analisis data dengan distribusi frekuensi, menunjukkan frekuensi persetujuan/pertidak setujuan responden terhadap kebutuhan setiap kompetensi di perusahaan/instansi tempat mereka bekerja. Pembahasan item kompetensi berdasarkan kelompok mata kuliahnya akan dibahas sebagai berikut:

Berdasarkan hasil analisa statistik dengan menggunakan SPSS memperoleh hasil dari 58 item kompetensi healing dan konseling, dapat disimpulkan bahwa secara garis besar responden berpendapat positif dengan memberikan pilihan jawaban "Sesuai", berdasarkan rata-rata dari ke-58 item tersebut yaitu 4.841 atau dibulatkan menjadi 5 . Perincian data tendensi sentral dari 58 item kompetensi tersebut terlampir.

Kemudian Blue print pembuatan kuesioner dapat dilihat pada Tabel 1 berikut: 
Tabel 1 . Kuesioner Kompetensi Lulusan Program Studi Healing Dan Konseling UAI

\begin{tabular}{|c|l|c|}
\hline No & \multicolumn{1}{|c|}{ Kelompok Mata Kuliah } & $\begin{array}{c}\text { No item } \\
\text { kompetensi }\end{array}$ \\
\hline \multicolumn{3}{|c|}{ Mata Kuliah Universitas } \\
\hline 1 & Mata Kuliah Dasar Umum & $1-7$ \\
\hline \multicolumn{2}{|c|}{ Mata Kuliah Fakultas dan Program Studi } \\
\hline 3 & $\begin{array}{l}\text { Mata kuliah berkaitan dengan } \\
\text { psikologi }\end{array}$ & $8-15$ \\
\hline 2 & Mata kuliah berkaitan dengan dakwah & $16-23$ \\
\hline 4 & $\begin{array}{l}\text { Mata kuliah berkaitan dengan ke- } \\
\text { Islaman }\end{array}$ & $24-30$ \\
\hline 5 & $\begin{array}{l}\text { Mata kuliah berkaitan dengan healing } \\
\text { dan konseling }\end{array}$ & $31-51$ \\
\hline 6 & $\begin{array}{l}\text { Mata kuliah berkaitan dengan ilmu } \\
\text { sosial }\end{array}$ & $52-55$ \\
\hline 7 & $\begin{array}{l}\text { Mata kuliah berkaitan dengan } \\
\text { penelitian ilmiah }\end{array}$ & $56-58$ \\
\hline
\end{tabular}

Berdasarkan tabel di atas, 58 item kompetensi tersebut dikelompokkan menjadi 7 kelompok mata kuliah. Hasil analisa data dengan mengelompokkan 58 item kompetensi tersebut pada 7 kelompok mata kuliah memperoleh hasil sebagai berikut:

Tabel 2. Statistics Berdasarkan Kelompok Mata Kuliah

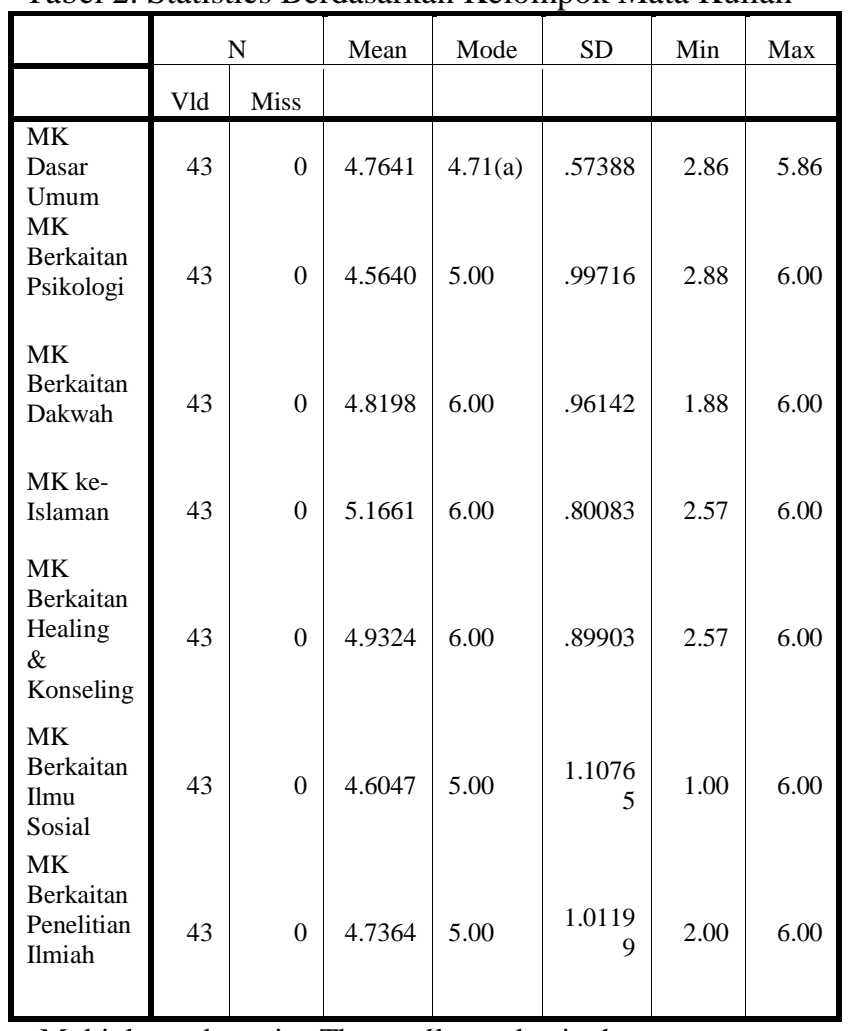

a Multiple modes exist. The smallest value is shown

Hasil analisis statistik untuk kelompok mata kuliah dasar umum adalah mean $=4.7641$ atau dibulatkan menjadi 5, Modus $=4.71$ dibulatkan 5, nilai minimum $=2.86$ dibulatkan 3 , dan nilai maksimum $=5.86$ dibulatkan 6. Kelompok mata kuliah ini terdiri dari kompetensi pada item nomor 1 sampai 7.

Kelompok mata kuliah yang berkaitan dengan psikologi terdiri dari kompetensi pada item nomor 8 sampai 15 . Hasil analisis statistiknya adalah mean $=4.5640$ atau dibulatkan menjadi 5 , Modus $=5$, nilai minimum $=2.88$ dibulatkan 3 , dan nilai maksimum $=6$.

Kemudian untuk kelompok mata kuliah yang berkaitan dengan ilmu dakwah, terdiri dari kompetensi pada item nomor 16 sampai 23. Hasil analisis statistiknya adalah mean $=4.8198$ atau dibulatkan menjadi 5 , Modus $=6$, nilai minimum $=$ 1.88 dibulatkan 2, dan nilai maksimum $=6$.

Kelompok mata kuliah yang berkaitan dengan ke-Islaman, terdiri dari kompetensi pada item nomor 24 sampai 30. Hasil analisis statistiknya adalah mean $=5.1661$ atau dibulatkan menjadi 5 , Modus $=6$, nilai minimum $=2.57$ dibulatkan 3, dan nilai maksimum $=6$.

Kompetensi pada item nomor 31 sampai 51 dikelompokkan pada kelompok mata kuliah yang berkaitan dengan healing dan konseling. Hasil analisis statistiknya adalah mean $=4.9324$ atau dibulatkan menjadi 5 , Modus $=6$, nilai minimum $=$ 2.57 dibulatkan 3, dan nilai maksimum $=6$.

Kelompok mata kuliah yang berkaitan dengan ilmu sosial terdiri dari nomor item 52 sampai 55. Hasil analisis statistiknya adalah mean $=4.6047$ atau dibulatkan menjadi 5 , Modus $=5$, nilai minimum $=1$, dan nilai maksimum $=6$.

Selanjutnya kelompok yang terakhir adalah kelompok mata kuliah yang berkaitan dengan penelitian ilmiah yang terdiri dari kompetensi pada item nomor 56 sampai 58. Hasil analisis statistiknya adalah mean $=4.7364$ atau dibulatkan menjadi 5 , Modus $=5$, nilai minimum $=2$, dan nilai maksimum $=6$.

Berdasarkan penjelasan di atas, dapat dibuat kesimpulan bahwa kelompok mata kuliah yang paling dibutuhkan di dunia kerja tempat respon bekerja adalah kelompok mata kuliah yang berkaitan dengan ke-Islaman dan kemudian yang berkaitan dengan healing dan konseling, terlihat dari nilai rata-rata (mean), nilai minimum dan maksimumnya yang lebih tinggi dari kelompok lainnya.

Berikutnya, bidang yang sesuai untuk kompetensi healing dan konseling berdasarkan hasil penelitian ini pada umumnya berhubungan dengan sumber daya manusia (SDM) atau Human Resources Department, sebagai konselor, terapis, pembimbing rohani/pendakwah, relawan untuk berbagai permasalahan keluarga, fisik, pendidikan, 
agama, hukum Islam, kekerasan, dan lain-lain. Penjelasan rinci terlampir.

\section{KESIMPULAN}

\section{Kesimpulan}

Berdasarkan analisis data yang sudah terkumpul, maka dapat ditarik kesimpulan :

1. Kompetensi lulusan Program Studi Healing dan Konseling UAI ternyata dibutuhkan di dunia kerja, karena responden berpendapat positif dengan memberikan pilihan jawaban "Sesuai".

2. Kebutuhan itu terutama pada kompetensi untuk mata kuliah yang berkaitan dengan keIslaman.

3. Selain kompetensi untuk mata kuliah yang berkaitan dengan ke-Islaman, dunia kerja juga membutuhkan kompetensi yang berkaitan dengan healing dan konseling.

4. Bidang yang sesuai untuk kompetensi healing dan konseling pada umumnya berhubungan dengan sumber daya manusia (SDM) atau human resources department, sebagai konselor, terapis, pembimbing rohani/pendakwah, relawan untuk berbagai permasalahan keluarga, fisik, pendidikan, agama, hukum Islam, dan kekerasan.

\section{Saran}

Berdasarkan temuan data tersebut, penulis memberikan saran supaya program studi Dakwah Healing dan Konseling diharapkan dapat terus dilanjutkan karena peluang bagi lulusannya terbuka cukup luas di dunia kerja. Masyarakat membutuhkan pendakwah yang memang memahami ilmu keIslaman sekaligus ilmu konseling sebagai sarana dalam menyampaikan dakwahnya. Masyarakat juga membutuhkan relawan untuk memecahkan berbagai permasalahan sosial yang dihadapi oleh masyarakat dengan pendekatan religius.

Sehubungan dengan hal itu, masyarakat perlu memperoleh banyak informasi yang memadai tentang program studi ini. Untuk itu dibutuhkan promosi yang sinergis dan atraktif dari pihak universitas dan program studi. Caranya antara lain adalah dengan sering mengadakan kegiatan di luar kampus, seperti pengabdian masyarakat, penelitian, praktikum, supaya masyarakat tahu akan keberadaan prodi ini. Mahasiswa lulusan healing dan konseling adalah mahasiswa yang sudah mendapatkan kompetensi pada tatanan praktek konseling di lapangan, tidak sebatas teoritis saja, untuk itu disarankan kepada mahasiswa lulusan program studi healing dan konseling agar dapat terus mengaplikasikan ilmu yang sudah didapatkan kepada masyarakat dan dunia kerja.

\section{DAFTAR PUSTAKA}

[1] Guilford, J. P., and Fruchter, Benjamin. (1978). Foundamental Statistics in Psychology and Education $6^{\text {th }}$ edition. Singapore: McGraw-Hill.

[2] Kerlinger, Fred. N. (2000). Asas-asas Penelitian Behavioral. Yogyakarta: Gadjah Mada University Press.

[3] Prasetyo, Bambang., \& Jannah, Lina Miftahul. (2005). Teori dan Aplikasi Metode Penelitian Kuantitatif. Jakarta: PT. Raja Grafindo Persada.

[4] Priyatno, Dwi. (2008). Mandiri Belajar SPSS untuk Analisis Data dan Uji Statistik. Yogyakarta: MediaKom.

[5] Pedoman akademik FDK Universitas Islam Negeri Jakarta. (2006). Jakarta.

[6] Taufiq, Muhammad Izzuddin. (2006). Panduan Lengkap \& Praktis Psikologi Islam. Jakarta : Gema Insani.

[7] Teichler U. (1997). Graduate employment: challenges for the higher education in the twentyfirst century. Higher Education in Europe Vol XXII No.1.

[8] Teichler U. (1999). Research on the relationship between higher education and the world of work: past achievements, problems and new challenges. Higher Education Vol 38. 
Tabel Frekuensi Jawaban Responden/Item

\begin{tabular}{|c|c|c|c|c|c|c|c|}
\hline & \multicolumn{2}{|c|}{$\bar{N}$} & \multirow[t]{2}{*}{ Mean } & \multirow[t]{2}{*}{ Mode } & \multirow[t]{2}{*}{ Std. Deviation } & \multirow[t]{2}{*}{ Minimum } & \multirow[t]{2}{*}{ Maximum } \\
\hline & Valid & Missing & & & & & \\
\hline Item 1 & 43 & 0 & 5.53 & 6 & .550 & 4 & 6 \\
\hline Item 2 & 43 & 0 & 5.14 & 5 & .639 & 4 & 6 \\
\hline Item 3 & 43 & 0 & 4.47 & 5 & 1.369 & 1 & 6 \\
\hline Item 4 & 43 & 0 & 3.77 & 4 & 1.428 & 1 & 6 \\
\hline Item 5 & 43 & 0 & 4.70 & 5 & .887 & 1 & 6 \\
\hline Item 6 & 43 & 0 & 4.60 & 4 & 1.003 & 1 & 6 \\
\hline Item 7 & 43 & 0 & 5.14 & 6 & .804 & 4 & 6 \\
\hline Item 8 & 43 & 0 & 4.56 & 5 & 1.385 & 1 & 6 \\
\hline Item 9 & 43 & 0 & 4.74 & 5 & 1.026 & 3 & 6 \\
\hline Item 10 & 43 & 0 & 4.63 & 5 & 1.113 & 2 & 6 \\
\hline Item 11 & 43 & 0 & 4.74 & 5 & 1.071 & 2 & 6 \\
\hline Item 12 & 43 & 0 & 4.74 & 5 & 1.093 & 3 & 6 \\
\hline Item 13 & 43 & 0 & 4.40 & 5 & 1.178 & 2 & 6 \\
\hline Item 14 & 43 & 0 & 4.49 & 4 & 1.009 & 3 & 6 \\
\hline Item 15 & 43 & 0 & 4.21 & 5 & 1.319 & 1 & 6 \\
\hline Item 16 & 43 & 0 & 4.98 & 6 & 1.144 & 1 & 6 \\
\hline Item 17 & 43 & 0 & 4.98 & 6 & 1.102 & 1 & 6 \\
\hline Item 18 & 43 & 0 & 4.95 & 5 & .872 & 3 & 6 \\
\hline Item 19 & 43 & 0 & 4.65 & 5 & 1.270 & 1 & 6 \\
\hline Item 20 & 43 & 0 & 5.02 & 6 & 1.058 & 3 & 6 \\
\hline Item 21 & 43 & 0 & 4.77 & 6 & 1.212 & 1 & 6 \\
\hline Item 22 & 43 & 0 & 4.35 & 5 & 1.361 & 1 & 6 \\
\hline Item 23 & 43 & 0 & 4.86 & $5(\mathrm{a})$ & 1.082 & 1 & 6 \\
\hline Item 24 & 43 & 0 & 5.42 & 6 & .932 & 1 & 6 \\
\hline Item 25 & 43 & 0 & 5.28 & 6 & 1.141 & 1 & 6 \\
\hline Item 26 & 43 & 0 & 5.16 & 6 & 1.045 & 1 & 6 \\
\hline Item 27 & 43 & 0 & 5.30 & $5(\mathrm{a})$ & .741 & 3 & 6 \\
\hline Item 28 & 43 & 0 & 4.77 & 4 & .895 & 3 & 6 \\
\hline Item 29 & 43 & 0 & 5.05 & 6 & .899 & 3 & 6 \\
\hline Item 30 & 43 & 0 & 5.19 & 5 & .982 & 1 & 6 \\
\hline Item 31 & 43 & 0 & 4.79 & 6 & 1.319 & 1 & 6 \\
\hline Item 32 & 43 & 0 & 5.19 & 6 & 1.118 & 1 & 6 \\
\hline Item 33 & 43 & 0 & 4.88 & 6 & 1.179 & 1 & 6 \\
\hline Item 34 & 43 & 0 & 5.40 & 6 & .760 & 4 & 6 \\
\hline Item 35 & 43 & 0 & 5.07 & 6 & 1.203 & 1 & 6 \\
\hline Item 36 & 43 & 0 & 5.26 & 6 & .978 & 2 & 6 \\
\hline Item 37 & 43 & 0 & 5.30 & 6 & .860 & 3 & 6 \\
\hline Item 38 & 43 & 0 & 4.91 & 6 & 1.211 & 2 & 6 \\
\hline Item 39 & 43 & 0 & 4.81 & 6 & 1.258 & 2 & 6 \\
\hline Item 40 & 43 & 0 & 4.86 & 5 & 1.146 & 2 & 6 \\
\hline Item 41 & 43 & 0 & 4.88 & 4(a) & .793 & 4 & 6 \\
\hline Item 42 & 43 & 0 & 4.81 & $5(\mathrm{a})$ & 1.139 & 1 & 6 \\
\hline Item 43 & 43 & 0 & 4.81 & 5 & 1.220 & 1 & 6 \\
\hline Item 44 & 43 & 0 & 5.09 & 5 & .921 & 3 & 6 \\
\hline Item 45 & 43 & 0 & 4.65 & 6 & 1.289 & 1 & 6 \\
\hline Item 46 & 43 & 0 & 4.84 & 6 & 1.252 & 1 & 6 \\
\hline Item 47 & 43 & 0 & 4.98 & 5 & .771 & 3 & 6 \\
\hline
\end{tabular}




\begin{tabular}{|l|l|l|l|r|r|r|r|} 
Item 48 & 43 & 0 & 4.77 & 5 & 1.130 & 1 & 6 \\
Item 49 & 43 & 0 & 4.93 & 6 & 1.142 & 1 & 6 \\
Item 50 & 43 & 0 & 4.44 & $5(\mathrm{a})$ & 1.278 & 1 & 6 \\
Item 51 & 43 & 0 & 4.91 & 5 & 1.151 & 1 & 6 \\
Item 52 & 43 & 0 & 4.74 & 5 & 1.197 & 1 & 6 \\
Item 53 & 43 & 0 & 4.67 & 5 & 1.190 & 1 & 6 \\
Item 54 & 43 & 0 & 4.37 & 5 & 1.254 & 1 & 6 \\
Item 55 & 43 & 0 & 4.63 & 5 & 1.092 & 1 & 6 \\
Item 56 & 43 & 0 & 4.65 & 5 & 1.044 & 2 & 6 \\
Item 57 & 43 & 0 & 4.84 & 5 & .998 & 2 & 6 \\
Item 58 & 43 & 0 & 4.72 & 5 & 1.098 & 2 & 6 \\
\hline
\end{tabular}

a Multiple modes exist. The smallest value is show 
INSTANSI SUBJEK PENELITIAN

\begin{tabular}{|c|c|c|c|c|c|}
\hline & & Frequency & Percent & Valid Percent & $\begin{array}{l}\text { Cumulative } \\
\text { Percent }\end{array}$ \\
\hline \multirow[t]{32}{*}{ Valid } & & 2 & 4.7 & 4.7 & 4.7 \\
\hline & Bank Indonesia & 1 & 2.3 & 2.3 & 7.0 \\
\hline & Dinas P2B Jkt & 2 & 4.7 & 4.7 & 11.6 \\
\hline & Garmen Jakarta & 1 & 2.3 & 2.3 & 14.0 \\
\hline & Kodim 0504 & 1 & 2.3 & 2.3 & 16.3 \\
\hline & Konsultan Perencanaan & 1 & 2.3 & 2.3 & 18.6 \\
\hline & P2TP2A Prop. DKI Jkt & 1 & 2.3 & 2.3 & 20.9 \\
\hline & PT. Bank Mandiri & 3 & 7.0 & 7.0 & 27.9 \\
\hline & PT. Berkah Gemilang & 1 & 2.3 & 2.3 & 30.2 \\
\hline & PT. BRI Syariah & 1 & 2.3 & 2.3 & 32.6 \\
\hline & PT. Garuda Indonesia & 4 & 9.3 & 9.3 & 41.9 \\
\hline & $\begin{array}{l}\text { PT. Kaltim Metanol } \\
\text { Industri }\end{array}$ & 1 & 2.3 & 2.3 & 44.2 \\
\hline & PT. Krakatau & 1 & 2.3 & 2.3 & 46.5 \\
\hline & PT. Krakatau Daya Listrik & 1 & 2.3 & 2.3 & 48.8 \\
\hline & PT. Krakatau Engineering & 1 & 2.3 & 2.3 & 51.2 \\
\hline & PT. Krakatau Medika & 1 & 2.3 & 2.3 & 53.5 \\
\hline & PT. Latinusa & 1 & 2.3 & 2.3 & 55.8 \\
\hline & PT. Mandiri Persero Tbk & 2 & 4.7 & 4.7 & 60.5 \\
\hline & $\begin{array}{l}\text { PT. Sahabat Karimah } \\
\text { Wisata }\end{array}$ & 1 & 2.3 & 2.3 & 62.8 \\
\hline & PT. Sewu Cemerlang & 1 & 2.3 & 2.3 & 65.1 \\
\hline & PTKS & 3 & 7.0 & 7.0 & 72.1 \\
\hline & Rotary Club of Purwokerto & 1 & 2.3 & 2.3 & 74.4 \\
\hline & Rotary Of Purwokerto & 1 & 2.3 & 2.3 & 76.7 \\
\hline & RS Jakarta & 1 & 2.3 & 2.3 & 79.1 \\
\hline & RS Swasta & 1 & 2.3 & 2.3 & 81.4 \\
\hline & RS Swasta Jakarta & 1 & 2.3 & 2.3 & 83.7 \\
\hline & $\begin{array}{l}\text { Rumah Bersalin Sayang } \\
\text { Bunda }\end{array}$ & 1 & 2.3 & 2.3 & 86.0 \\
\hline & Rumah Sakit Swasta & 3 & 7.0 & 7.0 & 93.0 \\
\hline & Swasta & 1 & 2.3 & 2.3 & 95.3 \\
\hline & TPPKK Kab Banyumas & 1 & 2.3 & 2.3 & 97.7 \\
\hline & $\begin{array}{l}\text { Yayasan Kesejahteraan } \\
\text { Umat Islam Indone }\end{array}$ & 1 & 2.3 & 2.3 & 100.0 \\
\hline & Total & 43 & 100.0 & 100.0 & \\
\hline
\end{tabular}

